\title{
Studi Pengaruh Beban Puncak Terhadap Susut Umur Transformator di PT PLN (Persero) Rayon Daya
}

\author{
Afriansyah $^{1)}$, Bakhtiar, ${ }^{2)}$ Thalib Bini $^{3)}$ \\ 1),2),3)Jurusan Teknik Elektro, Program Studi D4.Teknik Listrik, Politeknik Negeri Ujung Pandang \\ Email:ancaafr@yahoo.co.id ${ }^{1)}$,bakhtiar.poltekup@gmail.com ${ }^{2}$,ruslanlausu@gmail.com ${ }^{3)}$
}

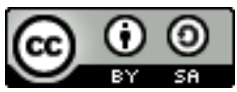

\begin{abstract}
Abstrak
Transformator berfungsi menyalurkan tenaga listrik dengan cara menaikkan atau menurunkan tegangan kemudian menyalurkan dari dari suatu rangkaian listirik ke rangkaian listrik lainnya. Transformator didesain dengan suhu sekitar $20^{\circ} \mathrm{C}$ tetapi beroperasi pada suhu lingkungan $30^{\circ} \mathrm{C}$ di Indonesia, maka transformator tersebut harus disesuaikan pembebanannya. Semakin tinggi suhu setempat semakin pendek operasional dan semakin besar susut umur dari transformator tersebut. Pemanasan pada belitan trafo dapat mengkibatkan isolasi menjadi rusak dan kenaikan temperatur minyak akan mengubah sifat serta komposisi minyak trafo. Apabila perubahan-perubahan tersebut dibiarkan akan mengakibatkan nilai isolasi dari minyak menurun. suhu belitan pada sebuah transformator dapat dipengaruhi oleh besarnya beban serta temperatur lingkungan. Perlu dianalisis nilai suhu belitan pada sebuah transformator berdasarkan standar IEC354 yang diterapkan yaitu maksimal $98^{\circ} \mathrm{C}$.

Pada tulisan ini meneliti pengaruh beban puncak terhadap susut umur transformator di PT.PLN (Persero) Rayon Daya. Hasil penelitian diperoleh pembebanan tranformator PT.IBT.007 dan transformator PT.IBT.SPTC masingmasing $90.3 \%$ dan $91.5 \%$. susut umur yang didapatkan sebesar $122 \%$ dan $136 \%$ sehingga sisa umur transformator diperkirakan 15 tahun dan 12 tahun.
\end{abstract}

Keywords: Transformator, Susut Umur, Suhu Lingkungan.

\section{PENDAHULUAN}

A. Latar Belakang

Transformator atau trafo sangat berperan penting dalam jaringan distribusi untuk menyalurkan tenaga listrik. Fungsi dari transformator ini adalah untuk mengubah energi listrik dari suatu rangkaian listrik ke rangkaian listrik lainnya.

Data beban puncak listrik adalah data beban pemakaian energi listrik maksimal yang tercatat berdasarkan waktu yaitu, harian, mingguan, maupun bulanan. Beban puncak ini biasanya terjadi pada pukul $17.00-22.00$. Beban puncak terjadi ketika kebutuhan listrik konsumen menanjak ke titik yang paling tinggi di satu waktu tertentu, baik dalam rentang waktu jam, hari, minggu, bulan, hingga tahun [5]

Menurut standar IEC354, sebuah transformator akan mengalami umur yang normal pada kondisi suhu Hot Spot $98^{\circ} \mathrm{C}$ pada pembebanan yang terusmenerus. Apabila transformator tersebut mengalami suhu Hot Spot yang melampaui dari $98^{\circ} \mathrm{C}$, maka susut umurnya akan begitu cepat sehingga dapat mengurangi umur transformator yang diharapkan.
Ketika suatu transformator dibebani berlebih secara terus-menerus akan membuat suhu pada $\mathrm{Hot}$ Spot menjadi panas sehingga suhu pada minyak transformator pun juga ikut menjadi panas dan hal tersebut membuat penyusutan umur transformator menjadi sangat cepat.Oleh karena itu penulis melaksanakan penelitian pengaruh beban puncak terhadapa susut umur transformator.

\section{KAJIAN LITERATUR}

\section{A. Transformator}

Transformator adalah peralatan listrik yang berfungsi untuk mengubah dan memindahkan energi listrik dari suatu rangkaian listrik ke rangkaian listrik lainnya dengan memanfaatkan prinsip induktansi elektromagnetik.

Secara sederhana transformator dapat dibagi menjadi tiga bagian, yaitu lilitan primer, lilitan sekunder dan inti besi. Lilitan primer merupakan bagian transformator yang terhubung dengan rangkaian sumber energi (catu daya). Lilitan sekunder merupakan bagian transformator yang terhubung dengan rangkaian beban. Inti besi merupakan bagian transformator yang bertujuan untuk mengarahkan keseluruhan fluks magnet 
yang dihasilkan oleh lilitan primer agar masuk ke lilitan sekunder. Gambar sederhana dari sebuah transformator dapat dilihat pada gambar 1.

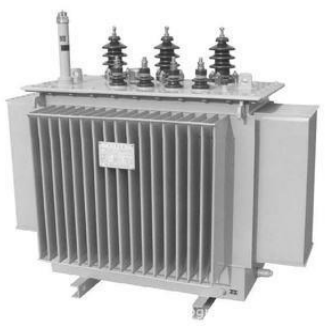

Gambar 1. Transformator

\section{B. Minyak Transformator}

Sebagian besar kumparan-kumparan dan inti trafo tenaga direndam dalam minyak trafo, terutama trafo-trafo tenaga yang berkapasitas besar, karena minyak trafo mempunyai sifat sebagai isolasi dan media pemindah, sehingga minyak trafo tersebut berfungsi sebagai media pendingin dan isolasi.

Di dalam sebuah transformator terdapat dua komponen yang secara aktif "membangkitkan" energi panas, yaitu besi (inti) dan tembaga (kumparan). Bila energi panas tidak disalurkan melalui suatu sistem pendinginan akan mengakibatkan besi maupun tembaga akan mencapai suhu yang tinggi, yang akan merusak nilai isolasinya. Untuk maksud pendinginan itu, kumparan dan inti dimasukkan ke dalam suatu jenis minyak, yang dinamakan minyak transformator. Minyak itu mempunyai fungsi ganda, yaitu pendinginan dan isolasi. Fungsi isolasi ini mengakibatkan berbagai ukuran dapat diperkecil. Perlu dikemukakan bahwa minyak transformator harus memiliki mutu yang tinggi dan senantiasa berada dalam keadaan bersih. Disebabkan energi panas yang dibangkitkan dari inti maupun kumparan, suhu minyak akan naik. Hal ini akan mengakibatkan terjadinya perubahan-perubahan pada minyak transformator. Lagi pula dalam jangka panjang waktu yang lama akan terbentuk berbagai pengotoran yang akan menurunkan mutu minyak transformator. Hal-hal ini dapat mengakibatkan kemampuan pendinginan maupun isolasi minyak akan menurun. Selanjutnya dapat pula terjadi bahwa hawa lembab yang sebagaimana halnya terjadi di daerah tropis, mengakibatkan masuknya air didalam minyak transformator.

\section{Susut Umur Transformator}

Penurunan kemampuan suatu bahan isolasi akibat panas disebut penuaan (aging). Hal ini merupakan faktor utama yang membatasi kemampuan mempertahankan perkiraan umur dari transformator distribusi. Dengan kata lain, akibat adanya pembebanan lebih akan menimbulkan panas pada lilitan kumparan transformator sehingga pada suatu saat akan menurunkan umur transformator (penyusutan umur) dari yang diharapkan.

Suhu belitan pada sebuah transformator dapat dipengaruhi oleh besarnya beban serta temperatur lingkungan. Perlu dianalisis nilai temperatur Hot Spot pada sebuah transformator berdasarkan standar IEC354 yang diterapkan yaitu maksimal $98^{\circ} \mathrm{C}$, apabila suhu belitan transformator telah melebihi 98 ${ }^{\circ} \mathrm{C}$ akan menyebabkan susut umur pada transformator. Untuk transformator yang menggunakan media pendingin air, maka temperatur air tidak boleh lebih dari $25^{\circ} \mathrm{C}$, sedangkan untuk transformator yang menggunakan media pendingin udara, maka temperatur udaranya tidak boleh lebih dari $40^{\circ} \mathrm{C}$ dan tidak boleh di bawah $-25^{\circ} \mathrm{C}$ untuk pemasangan luar dan tidak boleh di bawah $5^{\circ} \mathrm{C}$ untuk pemasangan dalam. Sebagai tambahan untuk pendinginan dengan udara, temperaturnya tidak melebihi rata-rata $30^{\circ} \mathrm{C}$ untuk satu hari.

\section{Waktu Beban Puncak dan Luar Beban Puncak}

PLN, mengenakan dua istilah untuk membedakan waktu pemakaian listrik para pelanggannya, yaitu : Waktu Beban Puncak (WBP) dan Luar Waktu Beban Puncak (LWBP). Disebut WBP karena waktu pemakaian listrik dikerjakan secara bersamaan oleh mayoritas masing-masing pelanggan PLN di dalam rumahnya. Batas rentang waktu yang termasuk kategori WBP, umumnya berlangsung antara pukul $17.00 \mathrm{~s} / \mathrm{d} \quad 22.00$. Sedangkan Luar Waktu Beban Puncak merupakan pemakaian listrik kebalikan dari Waktu Beban Puncak. Pada prakteknya, pemakaian listrik di saat WBP tidak selalu pasti berlangsung selama 5 jam (17.00 s/d 22.00). Tapi, kondisi pemakaian listrik WBP pasti akan terjadi dalam jeda waktu antara pukul pukul $17.00 \mathrm{~s} / \mathrm{d} 22.00$.

Kondisi pemakaian listrik di saat WBP tersebut, berakumulasi menjadi besar dan hampir selalu berimbas pada turunnya voltase listrik secara menyeluruh. Pemakaian perangkat listrik / elektronik di saat voltase sedang turun, akan "memaksa" perangkat bekerja lebih lama dan lebih berat. Itulah salah satu penyebab yang membuat pemakaian listrik di saat WBP menjadi lebih besar.

\section{E. Jenis-jenis Transformator Berdasarkan Penggunaannya}

1. Transformator Daya

Tranformator daya adalah suatu peralatan listrik yang berfungsi untuk menyalurkan daya listrik dari generator bertegangan menengah ke transmisi bertegangan tinggi dan untuk menyalurkan daya dari transmisi bertegangan tinggi ke jaringan distribusi bertegangan rendah. Gambar Konstruksi umum dari transformator daya dapat dilihat pada gambar 2 


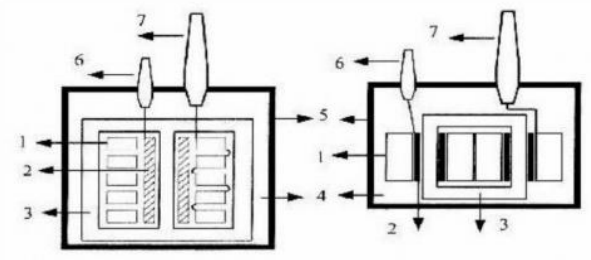

gambar 2.KonstruksiTransformator Daya

Keterangan :

1) Kumparan tegangan tinggi

2) Kumparan tegangan rendah

3) Inti

4) Minyak isolasi

5) Tanki baja

6) Bushing tegangan tinggi

7) Bushing tegangan rendah

Pada gambar terlihat bahwa bagian utama dari transformator adalah inti, dua set kumparan atau lebih dan isolasi. Inti trafo yang terbuat dari lembaran-lembaran baja silikon yang satu dengan lainnya diisolasi dengan pernis.

Kumparan terbuat dari bahan tembaga yang dihubungkan dengan sumber energi disebut kumparan primer, sedang yang dihubungkan dengan beban disebut kumparan sekunder.

2. Transformator Distribusi

Tujuan dari penggunaan transformator distribusi adalah untuk menaikkan dan menurunkan tegangan utama dari sistem distribusi listrik. Transformator distribusi yang umum digunakan adalah transformator stepdown 20kV/400V. Gambar Konstruksi umum dari transformator daya dapat dilihat pada gambar 3

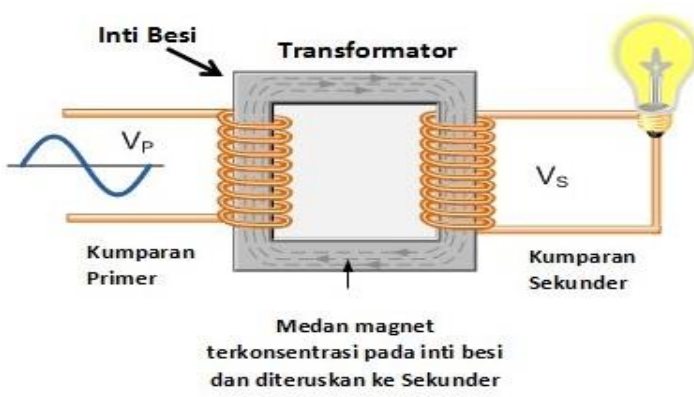

gambar 3. KonstruksiTransformator Distribusi

Transformator ini terdiri dari sebuah inti besi (core) dan dua buah lilitan yang biasa disebut lilitan primer dan lilitan sekunder dengan perbandingan.

$$
\text { Ns / Np = Ip / Is = Vs / Vp }
$$

Keterangan :

Ns $=$ Lilitan sekunder transformator

$\mathrm{Np}=$ Lilitan primer transformator

Is $=$ Arus sekunder transformator

$\mathrm{Ip}=$ Arus primer transformator

$\mathrm{Vp}=$ Tegangan primer transformator

$\mathrm{Vs}=$ Tegangan sekunder transformator

3. Transformator Pengukuran

Transformator pengukuran adalah suatu peralatan listrik yang berfungsi sebagai alat transformasi energi listrik yang digunakan sebagai alat ukur bantu untuk keperluan pengukuran tegangan dan arus listrik agar berada dalam jangkauan alat ukur, sehingga pengukuran arus dan tegangan listrik dapat terbaca oleh suatu alat ukur.Trafo pengukuran, ada 2 macam yaitu:

\section{A. Transformator Arus}

Transfomator arus merupakan trafo arus yang berfungsi untuk mengkonversi arus yang melewatinya dari level tinggi ke level rendah yang dapat dimanfaatkan untuk input alat pengukuran maupun alat proteksi pada suatu jaringan sistim tenaga lisrik.

Transformator arus merupakan komponen utama dalam sistim tenaga listrik, baik pada distribusi maupun pada pembangkitan. Dengan adanya transformator arus, suatu peralatan ataupun jaringan dapat dimonitoring kondisinya melalui hasil pengukuan serta dapat dilindungi melalui proteksi apabila adanya gangguan yang menimbulkan arus yang sangat besar sebagai akibat short circuit (hubungan singkat) ataupun overload (kelebihan beban) dan lain sebagainya.

B. Transformator Tegangan

Transformator tegangan adalah transformator yang berfungsi untuk mentransformasikan nilai tegangan yang tinggi pada sisi primer ke nilai tegangan yang rendah di sisi sekunder yang digunakan untuk pengukuran (metering) dan proteksi. Fungsi lainnya ialah mengisolasi rangkaian sekunder terhadap rangkaian primer, yaitu memisahkan instalasi pengukuran dan proteksi dari tegangan tinggi.

Prinsip Kerja Transformator Tegangan bekerja berdasarkan prinsip elektromagnetik, Jika pada kumparan primer mengalir arus I1, maka pada kumparan primer timbul gaya gerak magnet sebesar N1I1. Gaya gerak magnet ini memproduksi 
fluks pada inti, kemudian membangkitkan gaya gerak listrik (GGL) pada kumparan sekunder. Jika terminal kumparan sekunder tertutup, maka pada kumparan sekunder mengalir arus $\mathrm{I} 2$, arus ini menimbulkan gaya gerak magnet N1I1 pada kumparan sekunder

\section{METODE PENELITIAN}

\section{A. Tempat dan Waktu Penelitian}

Tempat penelitian dilaksanakan di wilayah PT.PLN (Persero) Unit Layanan Pelanggan Daya yang beralamat di Jl. Batara Bira No. 3 Kec. Biringkanaya, Makassar, Terkhusus meneliti pengukuran beban puncak yang terdapat pada Penyulang Bontoa. Waktu Penelitian dan pengambilan data berlangsung selama 7 bulan yang dilaksanakan mulai pada bulan januari 2019 - Juli 2019.

\section{B. Metode Pengumpulan Data}

Metode Pengumpulan Data yang dilakukan ada 3 cara yaitu:

1. Metode Literatur

Dimana dilakukan pengumpulan data dari berbagai referensi- referensi buku yang berhubungan dengan judul tulisan ini untuk mendapatkan dan mengetahui dasar-dasar teori yang ada hingga dapat menunjang dalam penulisan ini.

2. Metode Obsevasi

Dimana dilakukan pengumpulan data dan keterangan serta mengamati peralatan atau sistem yang ada secara langsung di PT.PLN (Persero) Unit Layanan Pelanggan Daya.

3. Metode Wawancara

Dimana dilakukan tanya jawab secara langsung dengan pihak-pihak dan staf yang bertaggung jawab di PT.PLN (Persero) Unit Layanan Pelanggan Daya.

\section{Teknik Analisis Data}

Setelah semua data diperoleh dianggap lengkap, kemudian dilakukan pengolahan data, selanjutnya data- data tersebut kemudian dianalisis menggunakan persamaan-persamaan yang terdapat pada standar IEC 354.

\section{HASIL DAN PEMBAHASAN}

A. Data Penelitian

Tabel 1 Data Pengukuran Beban Puncak

\begin{tabular}{ccccc}
\hline $\begin{array}{c}\text { Kode } \\
\text { Gardu }\end{array}$ & $\begin{array}{c}\text { Kapasitas } \\
(\mathbf{k V A})\end{array}$ & $\begin{array}{c}\text { Tanggal } \\
\text { Ukur }\end{array}$ & Jam & $\begin{array}{c}\text { \% Beban } \\
\text { Trafo }\end{array}$ \\
\hline PT.IBT.024 & 160 & $\begin{array}{c}12 \mathrm{Nov} \\
2018\end{array}$ & $19: 29$ & 80.84 \\
\hline PT.IBT.007 & 200 & $\begin{array}{c}02 \mathrm{Nov} \\
2018\end{array}$ & $20: 16$ & 90.3 \\
\hline PT.IBT.049 & 200 & $\begin{array}{c}15 \mathrm{Nov} \\
2018\end{array}$ & $20: 19$ & 88.99 \\
\hline PT.IBT.SPTC & 200 & $\begin{array}{c}23 \mathrm{Nov} \\
2018\end{array}$ & $19: 42$ & 91.5 \\
\hline
\end{tabular}

\section{B. Pembahasan}

Analisa perhitungan yang digunakan pada penelitian kali ini berupa perhitungan susut umur dan menentukan perkiraan umur transformator yang mengacu pada standar IEC354

1. Menghitung Susut Umur dan Menentukan Perkiraan umur transformator PT.IBT.SPTC

* Mentukan Ratio Pembebanan

$$
K=\frac{\text { Beban Transformator }}{\text { Kapasitas Transformator }} \text { (1) }
$$

$$
\begin{gathered}
K=\frac{183.01}{20 n} \\
K=0.91 \mathrm{kVA}
\end{gathered}
$$

$*$

Rugi (d)

Menentukan Perbandingan

Unutk nilai rugi tembaga pada daya pengenal dan rugi besi tak berb

eban berdasarkan SPLN:1982

$d=\frac{\text { Rugi tembaga pada daya pengenal }}{\text { Rugi Besi }}$

$d=\frac{2.85}{0.55}$

$d=5.18 W$

$$
\begin{aligned}
& \text { Temperatur Stabil Top Oil } \\
& \Delta \theta_{b}=\Delta \theta_{b r}\left[\frac{1+d K^{2}}{1+d}\right]^{X}
\end{aligned}
$$

Untuk ONAN $\Delta \theta_{b r}=55$ dan $\mathrm{x}=0.9$

$$
\text { Untuk OFAF } \Delta \theta_{b r}=40 \text { dan } \mathrm{x}=1
$$

$$
\begin{aligned}
\Delta \theta_{b} & =55\left[\frac{1+5.18(0.91)^{2}}{1+5.18}\right]^{0,9} \\
\Delta \theta_{b} & =55\left[\frac{1+4.28}{6.18}\right]^{0,9} \\
\Delta \theta_{b} & =55\left[\frac{5.28}{6.18}\right]^{0,9} \\
\Delta \theta_{b} & =47.73^{\circ} \mathrm{C}
\end{aligned}
$$

enentukan Selisih Temperatur Antara Hot Spot dengan Top Oil

$$
\Delta \theta_{t d}=\left(\Delta \theta_{c r}-\Delta \theta_{b r}\right)\left(K^{2 y}\right)
$$


Untuk ONAN $\Delta \theta_{c r}=78^{\circ} \mathrm{C}, \Delta \theta_{b r}=55^{\circ} \mathrm{C}$ dan $\mathrm{y}=$ 0.8

Untk OFAF $\Delta \theta_{c r}=78^{\circ} \mathrm{C}, \Delta \theta_{b r}=40^{\circ} \mathrm{C}$ dan $\mathrm{y}=$ 0.9

$\Delta \theta_{t d}=(78-55)(0.91)^{2(0,8)}$

$\Delta \theta_{t d}=(23)(0.91)^{1,6}$

$\Delta \theta_{t d}=19.77^{\circ} \mathrm{C}$

enentukan Temperatur Hot Spot

$\theta_{c}=\left(\theta_{a r}+\Delta \theta_{b r}+\Delta \theta_{t d}\right)$

$\theta_{\text {ar }}=\frac{\sum \theta_{a} \text { maks } / \text { hari }}{\sum \text { hari }}$

$32+32+32+32+32+32+32+30+31+32$ PT 32 LT +002

$+32+33+33+33+32+32+32+32+29+31+31$

$\theta_{\text {ar }}=\frac{+31+28+32+32+33+32+32}{30}$

$\theta_{\text {ar }}=\frac{951}{30}$

$\theta_{\text {ar }}=\frac{951}{30}$

$\theta_{\text {ar }}=31.7^{\circ} \mathrm{C}$

Maka :

$\theta_{c}=31.7+47.73+19.77$

$\theta_{c}=99.2^{\circ} \mathrm{C}$

enentukan Laju Penuan Thermal Relatif

$V=2^{(\theta C-98) / 6}$

$V=2^{(99.2-98) / 6}$

$V=2^{(1.2) / 6}$

$V=1.14$

enghitung Pengurangan Umur

$L=\frac{h}{3 T} \times 100 \%$

$L=\frac{1}{3 \times 5} \times\left\{V_{0}+\sum 4 V_{\text {odd }}+\sum 2 V_{\text {even }}+V_{n}\right\} \times 100 \%$

$L=\frac{1}{15} \times\{1.14+4(1.14+1.14+1.14)+2(1.14+1.14)$

$L=\frac{1}{15} \times\{20.52\} \times 100 \%$

$L=136 \%$

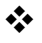

enghitung Perkiraan Umur Transformator

sisa umur $=\frac{\text { umur dasar }-n}{\text { susut umur }}$

Umur dasar dari transformator diperkirakan 20

tahun. Untuk tahun pengoperasian trafo PT.IBT.

SPTC ialah pada tahun 2015.

sisa umur $=\frac{20-(2018-2015)}{136 \%}$
sisa umur $=\frac{20-3}{136 \%}$
sisa umur $=\frac{17}{1.36}$

\section{sisa umur $=12$ tahun}

Untuk data lainnya dihitung dengan menggunakan persamaan yang sama sehingga di dapat hasilnya seperti tabel 2 berikut :

Tabel 2 Hasil Perhitungan Susut Umur Transformator

\begin{tabular}{|c|c|c|c|c|c|}
\hline KAde Gardu & $\begin{array}{c}\text { Tahun } \\
\text { Pengoperas } \\
\text { ian }\end{array}$ & $\begin{array}{l}\Delta \theta_{b r} \\
{ }^{\circ} \mathrm{C}\end{array}$ & $\begin{array}{c}\Delta \theta_{t d} \\
{ }^{\circ} \mathrm{C}\end{array}$ & $\begin{array}{c}\mathrm{L} \\
(\%)\end{array}$ & $\begin{array}{c}\text { Perkiraa } \\
\text { n Umur } \\
\text { (Tahun) }\end{array}$ \\
\hline PT.IBT.024 & 2015 & $\begin{array}{c}40.6 \\
4\end{array}$ & $\begin{array}{c}16.0 \\
9\end{array}$ & 39.6 & $>20$ \\
\hline $\begin{array}{c}32+32+32 \\
+31+31\end{array}$ & 2017 & 47 & $\begin{array}{c}19.4 \\
3\end{array}$ & 122 & 15 \\
\hline PT.IBT.049 & 2012 & 43.7 & $\begin{array}{c}18.7 \\
4\end{array}$ & 76 & 18 \\
\hline PT.IBT.SPTC & 2015 & $\begin{array}{c}47.7 \\
3\end{array}$ & $\begin{array}{c}19.7 \\
7\end{array}$ & 136 & 12 \\
\hline
\end{tabular}

Dari data dapat dilihat bahwa jumlah total transformator ada 4 unit yang terdiri dari transformator 3 fasa yaitu $160 \mathrm{kVA} 1$ unit, dan 200 kVA 3 unit. Terdapat 2 unit transformator yang terbeban di atas $80 \%$, dan 2 unit memiliki beban di atas $100 \%$ dari rating daya transformator.

M Dari hasil perhitungan yang dilakukan pada transformator dengan kode gardu PT.IBT.024 yang memiliki beban $80.84 \%$.pada tabel 4.2. Dapat dilihat bahwa Transformator PT.IBT.007 mulai difungsikan pada tahun 2015, susut umur pada transformator ini masih normal atau tidak banyak berpengaruh pada umur pemakaian transformator. PerMiraan sisa umur transformator masih di atas 20 tahun atau masih sesuai standar yang telah ditentukan. Begitu pula dengan transformator kode gardu PT.IBT.049 transformator ini masih sesuai standar yang telah ditentukan karena suhu belitannya tidak melebih $98^{\circ} \mathrm{C}$.

$+1.14\} \times \mathrm{Unad} \%$ hasil perhitungan transformator dengan beban di atas $90 \%$ dari rating daya transformator pada tabel 4.2. Dapat dilihat bahwa transformator dengan beban di atas $90 \%$ mengalami susut umur yang besar, seperti transformator PT.XPT.007 90.3\%.. Transformator PT.IBT.007 mulai difungsikan pada tahun 2017, berdasarkan hasil perhitungan perkiraan sisa umur yang di dapat kurang lebih 15 tahun untuk transformator PT.IBT.007. Berarti transformator ini mengalami penyusutan umur kurang lebih 5 tahun dari umur dasar transformator itu sendiri. Untuk grafik perbandingan umur transformator PT.IBT.007 yang normal dan setelah mengalamin penyusutan umur akibat pembebanan lebih pada saat beban puncak dapat dilihat pada grafik 1 sebagai berikut : 


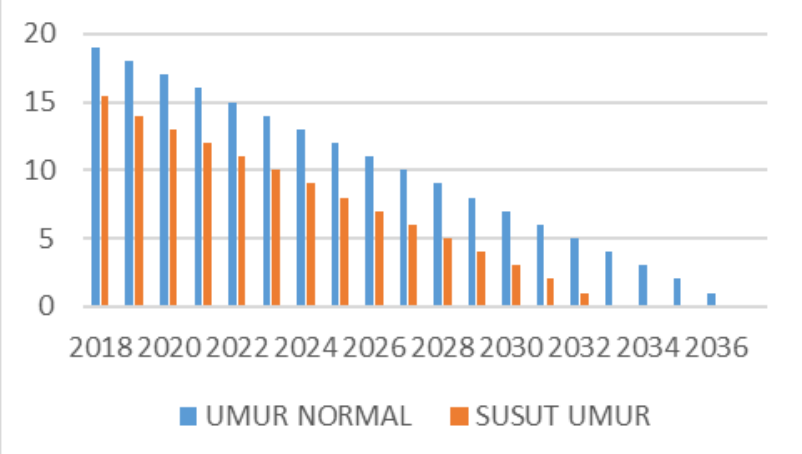

Grafik 1 perkiraan umur transformator PT.IBT.007

Untuk hasil perhitungan transformator dengan beban di atas 90\% lainnya dari rating daya transformator pada tabel 4.2 ialah trabsformator PT.IBT.SPTC 91.5\%. Transformator PT.IBT.SPTC mulai difungsikan pada tahun 2015, berdasarkan hasil perhitungan perkiraan sisa umur yang di dapat kurang lebih 12 tahun untuk transformator PT.IBT.SPTC. Berarti transformator ini mengalami penyusutan umur kurang lebih 5 tahun dari umur dasar transformator itu sendiri. Untuk grafik perbandingan umur transformator PT.IBT.SPTC yang normal dan setelah mengalamin penyusutan umur akibat pembebanan lebih pada saat beban puncak dapat dilihat pada grafik 2 sebagai berikut :

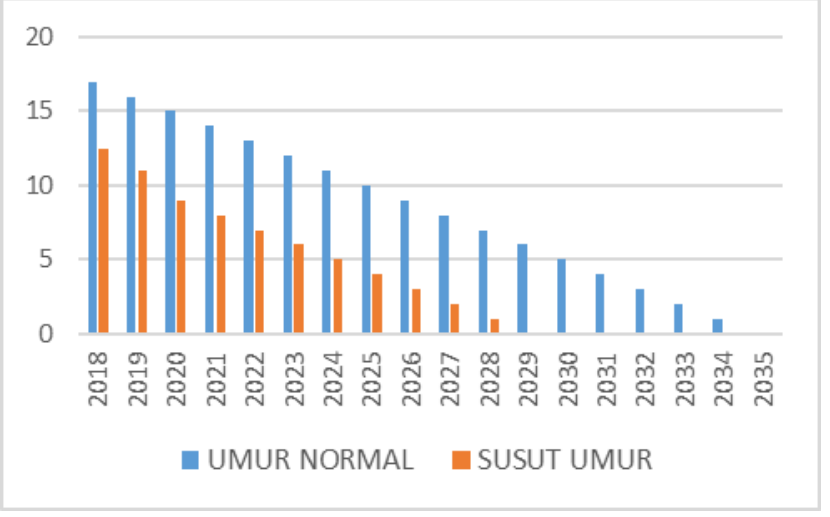

Grafik 2 perkiraan umur transformator PT.IBT.SPTC

Semakin besar pembebanan dan suhu sekitar pada suatu transformator maka semakin panas pula suhu minyak dan suhu belitannya sehingga menyebabkan penyusutan umur transformator semakin cepat. Hubungan antara pembebanan dan penyusutan umur transformator dapat dilihat pada grafik 3 berikut :

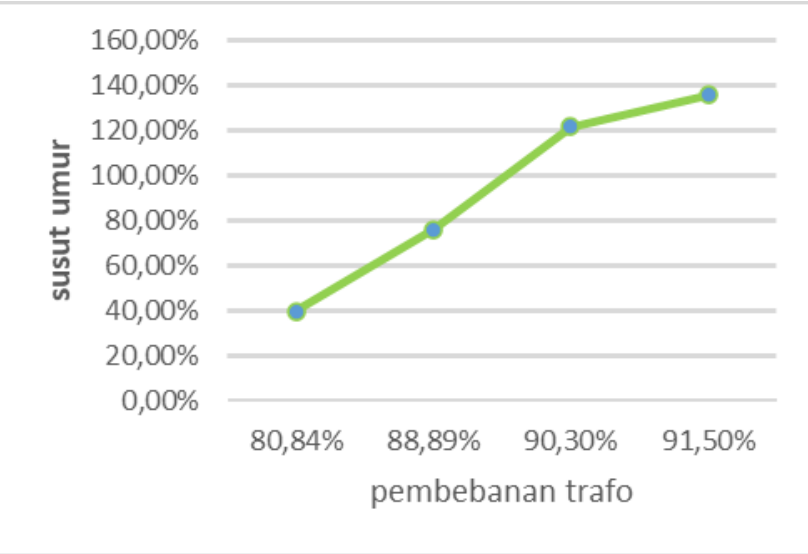

Grafik 3 Hubungan Antara Pembebanan dengan Susut Umur Trafo

2. Analisa Optimum

Berdasarkan standar IEC 354 Suatu transformator akan mengalami penyusutan apabila suhu belitannya melebihi $98^{\circ} \mathrm{C}$. Dari penelitian yang dilakukan transformator yang mengalami penyusutan umur ialah ketika transformator dibebani $90 \%$ atau lebih karena suhu belitan pada saat kondisi pembebanan tersebut melebihi $98^{\circ} \mathrm{C}$. maka untuk pembebanan $90 \%$ dapat dihitung pada temperatur maksimal berapa agar menghasilkan temperatur hotspot $98^{\circ} \mathrm{C}$ sebagai berikut:

* Trafo PT.IBT. 007 ( Beban 90.3\% )

Besarnya $\Delta \theta_{t d}$ dan $\Delta \theta_{b r}$ dapat dilihat pada tabel 4.2 didapatkan nilai $\Delta \theta_{t d}=19.43^{\circ} \mathrm{C}$ dan $\Delta \theta_{b r}=47^{\circ} \mathrm{C}$ sehingga:

$$
\begin{aligned}
& \theta_{c}=\left(\theta_{a r}+\Delta \theta_{b r}+\Delta \theta_{t d}\right) \\
& 98=\left(\theta_{a r}+47+19.43\right) \\
& \theta_{a r}=98-66.43 \\
& \theta_{a r}=31.5^{\circ} \mathrm{C}
\end{aligned}
$$

* Trafo PT.IBT.SPTC ( Beban 91.5\% )

Besarnya $\Delta \theta_{t d}$ dan $\Delta \theta_{b r}$ dapat dilihat pada tabel 4.2 didapatkan nilai $\Delta \theta_{t d}=19.77^{\circ} \mathrm{C}$ dan $\Delta \theta_{b r}=47.73^{\circ} \mathrm{C}$ sehingga:

$$
\begin{aligned}
& \theta_{c}=\left(\theta_{a r}+\Delta \theta_{b r}+\Delta \theta_{t d}\right) \\
& 98=\left(\theta_{a r}+47.73+19.77\right) \\
& \theta_{a r}=98-67.5 \\
& \theta_{a r}=30.5^{\circ} \mathrm{C}
\end{aligned}
$$

Jadi suhu sekitar maksimum agar temperatur hotspot tidak melebihi $98^{\circ} \mathrm{C}$ untuk pembebanan $90.3 \%$ adalah $31.5^{\circ} \mathrm{C}$ dan $30.5^{\circ} \mathrm{C}$ untuk pembebanan $91.5 \%$. Untuk mengurangi susut umur transformator akibat pembebanan lebih pada saat beban puncak selain memperhatikan suhu sekitar, juga dapat dilakukan mutasi gardu ataupun dilakuan trafo sisipan untuk mengurangi pembebanan pada transformator sehingga susut umur dari suatu transformator juga menurun.. 


\section{KESIMPULAN}

Berdasarkan proses yang telah dilakukan pada tulisan ini, mulai dari perhitungan dan analisis, dapat disimpulkan beberapa hal antara lain :

1. Semakin besar pembebanan suatu transformator maka semakin besar pula susut umurnya hal ini berdasarkan analisa yang telah dilakukan terhadap 4 unit transformator, terdapat 2 transformator yang suhu belitannya melewati standar IEC354 yaitu Transformator dengan kode gardu (PT.IBT.007) yang dibebani dengan sebesar 90.3\% dengan kapasitas $200 \mathrm{kVA}$ dengan sistem pendingin ONAN, suhu belitannya sebesar $98.13^{\circ} \mathrm{C}$ sehingga susut umurnya sebesar $122 \%$ dan sisa umurnya diperkirakan sebesar 15 tahun dan transformator dengan kode gardu (PT.IBT.SPTC) yang dibebani dengan beban 91.5\% dengan kapasitas $200 \mathrm{kVA}$ dengan sistem pendingin ONAN, suhu belitannya sebesar $99.2^{\circ} \mathrm{C}$ sehingga susut umurnya sebesar $122 \%$ dan sisa umurnya diperkirakan sebebsar 12 tahun.

2. Suhu belitan pada sebuah transformator berdasarkan standar IEC354 yang diterapkan yaitu maksimal $98^{\circ} \mathrm{C}$, agar suhu belitannya tidak melebihi $98{ }^{\circ} \mathrm{C}$, maka suhu udara sekitar transformator dengan kode gardu (PT.IBT.007) yang dibebani dengan sebesar 90.3\% dengan kapasitas $200 \mathrm{kVA}$ dengan sistem pendingin ONAN maksimal $31.5^{\circ} \mathrm{C}$ dan untuk transformator dibebani dengan beban $91.5 \%$ dengan kode gardu (PT.IBT.SPTC) dengan kapasitas $200 \mathrm{kVA}$ dengan pembebanan $91.5 \%$ suhu udara sekitarnya maksimal $30.5^{\circ} \mathrm{C}$ agar penyusutan umur transformator tidak terlalu cepat. Untuk mengurangi susut umur pada transformator akibat pembebanan lebih pada saat beban puncak dapat dilakukan dengan 3 cara yaitu dengan pengalihan beban, meningkatkan kapasitas transformator (uprating) atau memasang transformator sisipan.

\section{UCAPAN TERIMA KASIH}

Penulis menyampaikan ucapan terimakasih kepada PT.PLN(Persero) Rayon Daya yang telah membantu dan memfasilitasi penulis dalam penyusunan tulisan ini.

\section{REFERENSI}

[1] Aprianaldo, Doni dan Anntonov. 2015. "Skripsi Optimasi Penyeimbang Beban Trafo Distribusi Tterhadap Susut Beban.
[2] Fauzi, Muhammad. 2014. "Pengaruh Pembebanan Terhadap Umur Pemakaian Transformator Distribusi $20 \mathrm{kV}$ Daerah Kerja PT.PLN (Persero) Rayon Binjai Timur " :.Politeknik Negeri Medan

[3] IEC, Loading Guide For Oil Immersed Transformer, IEC Publication, 1972

[4] Kristiana, Ana. 2015. "Skripsi Peramalan Beban Puncak Pemakaian Listrik di Area Semarang Dengan Metide Hybrid Arima (Autoregressive Integrated Moving Avarage) - Anfis (Adaptive Neuro Fuzzy Inference system)". Universitas Diponegoro

[5] Mujiman dan Priyosusilo, L.2012. "Permodelan Beban Puncak Gardu Induk Waters dengan Program Aplikasi Microsoft EXCEL". Yogyakarta : Prosiding Seminar Nasional Aplikasi Sains dan Teknologi (SNAST) Periode III.

[6] Sofyan, dan Herawati Afriyastuti. 2015. "Skripsi Pengaruh Pembebanan Terhadap Efisiensi dan Usia Trasformator IV Gardu Induk Sukamerindu Bengkulu"

[7] SPLN-17. 1979. "Pedoman Pembebanan Transformator Terendam Minyak".

[8] Wibowo Helmi., Yadi Mulyadi dan Ade Gafar Abdullah. 2012. "Peramalan Beban Listrik Jangkan Pendek Terklasfikasi Berbasis Metode Autoregressive Integrated Moving Avarage" 